\title{
DAS ORDENAÇÕES AO ORDENAMENTO: A TRAJETÓRIA DO DIREITO DE PROPRIEDADE NO BRASIL
}

\author{
Gislene Pereira* \\ *Universidade Federal do Paraná, Programa de Pós-graduação em Planejamento Urbano, Curitiba, PR, Brasil
}

\begin{abstract}
Resumo
Este texto apresenta a trajetória do conceito de direito de propriedade no Brasil. Identificando as Ordenações Filipinas como a origem histórica das normas legais que regem os direitos de propriedade no país, é feito um reconhecimento das permanências e transformações do conceito ao longo do tempo. Por meio da análise dos principais documentos legais de alcance nacional, o texto acompanha o processo de transformação do conceito de propriedade, delimitando os momentos de inflexão. Com base nesse cenário, discute-se o futuro do conceito, considerando as condições em que ocorre a crescente urbanização do Brasil. Por fim, questiona-se a possibilidade de a trajetória analisada incorporar o uso como aspecto definidor das relações de propriedade.
\end{abstract}

Palavras-chave

Propriedade; Uso do Solo; Legislação Urbanística. 


\author{
ARTICLES \\ PLANNING AND PUBLIC POLICIES
}

\title{
FROM ORDINANCES TO LEGAL NORMS: THE TRAJECTORY OF PROPERTY RIGHTS IN BRAZIL
}

\author{
Gislene Pereira* \\ *Universidade Federal do Paraná, Programa de Pós-graduação em Planejamento Urbano, Curitiba, PR, Brazil
}

\begin{abstract}
This text presents the trajectory of the concept of property rights in Brazil. Identifying the Philippine Ordinances as the historical origin of the legal norms that govern property rights in Brazil, this paper recognizes the permanence and transformations of the concept over time. Through the analysis of key legal documents of a national scope, the text follows the transformation process of the concept of property, defining the moments of inflection. From within this scenario, the future of the concept is discussed, considering the conditions in which the growing urbanization in Brazil occurs. Lastly, it is questioned whether it is possible for the analyzed trajectory to incorporate use as a defining aspect of property relations.
\end{abstract}

Keywords

Property; Land Use; Urban Law. 


\title{
DAS ORDENAÇÕES AO ORDENAMENTO: A TRAJETÓRIA DO DIREITO DE PROPRIEDADE NO BRASIL
}

\author{
Gislene Pereira
}

Notas introdutórias: a trajetória de um conceito

Este trabalho parte das palavras de Rodota (1990, apud COSTALDELLO, 2006, p. 15): “[...] de tempos em tempos há um renascimento da questão proprietária [...] o enigma da propriedade permanece intacto diante de nós [...] e restaura a antiga grandeza”.

Coutinho, Prol e Miola (2018) reforçam essa afirmação, ao revelar que "a propriedade encarna um conjunto de relações sociais juridificadas, isto é, formalizadas e mediadas por normas e instituições jurídicas”. Nessas condições, as formas que assumem os direitos sobre a propriedade "[...] traduzem escolhas passadas, perenizando arranjos distributivos, definindo e legitimando quem ganha e quem perde por meio de institutos jurídicos que regulam como se dá a aquisição, a transferência e a perda da propriedade e da posse" (COUTINHO; PROL; MIOLA, 2018, p. 13).

É a partir desse reconhecimento da relação entre propriedade e sociedade que Rabello (2016) indica a necessidade de compreender a trajetória histórica do conceito de propriedade. Afinal, como a autora declara, a regulação do uso da propriedade nos séculos XIX e XX não poderia ser a mesma que a da sociedade urbana no século XXI. Se a sociedade se transformou, a propriedade também teve que se transformar. Ou seja, o conceito e o conteúdo do direito de propriedade se adaptam continuamente, acompanhando as transformações pelas quais a sociedade passa.

Diante desse contexto, este trabalho se propõe apresentar a trajetória do conceito de direito de propriedade no Brasil, identificando as diferentes formas que assumiu a organização jurídica da relação entre as pessoas e a terra. 
Com base nessa identificação, especulam-se possíveis caminhos das relações de propriedade, recuperando-se, para isso, o uso como um direito e o conceito de comum, de Dardot e Laval (2017).

\section{No princípio era o uso: os fundamentos da propriedade}

Para Assis (2008, p. 782), a apropriação da terra, de forma individual ou coletiva, desenvolve-se quase que "conjuntamente com a transição da fase do homem selvagem para a do homem sedentário, quando a civilização se assenta sobre determinados espaços físicos, retirando da terra seu sustento e valores”. No entanto, segue o autor (ASSIS, 2008, p. 785), a "positivação da propriedade como um direito absoluto encontra respaldo nos movimentos liberais que culminaram na elaboração das constituições francesas, de 1789[,] e norte-americana, de 1787”. Foi com base nessas duas cartas legais que a propriedade passou a ser um direito positivo', absoluto, imprescritível e inalienável. Contudo, com a Revolução Industrial, no final do século XVIII, o absolutismo desse direito começa a ser contestado. Na Constituição de Weimar, de 1919, a propriedade deixou de ser vista apenas como direito; a ela passam a ser associadas também obrigações: "A propriedade obriga. Seu uso deve, ao mesmo tempo, servir ao bem-estar social” (ASSIS, 2008, p. 785).

Ao analisar a situação do Brasil nesse contexto, constata-se que a questão da apropriação da terra aparece desde as capitanias hereditárias. Instituído por D. João III, a partir de 1532, o regime das capitanias tinha o objetivo de incentivar o povoamento do território. Regulamentado pelas Ordenações Manuelinas e, posteriormente, pelas Ordenações Filipinas, o instituto dividiu o território em porções (capitanias), as quais foram doadas a particulares (capitães donatários); a estes foi outorgado o poder de distribuir terras. Essa forma de distribuição de terras se denominava sesmaria. Cabe esclarecer que as Ordenações Filipinas correspondem a uma compilação de leis ordenada por Filipe I, rei da Espanha e Portugal. Chegaram ao Brasil com D. João VI e a Família Real e regeram o ordenamento jurídico em matéria civil até 1916, quando foi aprovado o Código Civil (ALMEIDA, 1985).

Nozoe (2006) afirma que as sesmarias constituíam o regime juridico básico da terra no Brasil Colônia. O autor chama a atenção para o fato de o regime de sesmarias ter sido trazido para o Brasil como uma transferência direta da legislação

\footnotetext{
1. Direito natural corresponde àquele adquirido ao nascer, decorrente de um conjunto de princípios e valores, é imutável e com validade em todo lugar. Direito positivo corresponde às normas definidas pelos homens, sendo, portanto, válido somente em determinados locais e passível de ser alterado. LAMOUNIER, M. A. O direito natural e o direito positivo e seu contexto histórico: Lições de Norberto Bobbio. Revista Âmbito Jurídico, $\mathrm{n}^{\circ}$ 163, ano XX, ago. 2017. Disponível em: https://ambitojuridico.com. br/edicoes/revista-163/o-direito-natural-e-o-direito-positivo-e-seu-contexto-historico-licoes-de-norberto-bobbio/. Acesso em: 18 maio 2019.
} 
portuguesa, concebida para enfrentar peculiaridades das terras pertencentes ao reino de Portugal. A simples transferência das normas, sem considerar as características do território brasileiro, extenso e desocupado, acabou por definir um regime de ocupação bastante confuso e de difícil controle.

Inicialmente, as sesmarias eram concedidas apenas a cidadãos portugueses; somente no ano de 1808 foi permitida a concessão a estrangeiros. As únicas exigências impostas ao sesmeiro eram o pagamento do dízimo à Ordem de Cristo e o cultivo da terra, dentro de um prazo definido, que podia variar de dois a cinco anos. Caso não se comprovasse o cultivo, a concessão era retirada e a terra voltava a domínio público. A Ordem Militar de Cristo foi instituída pelo rei D. Dinis em 1318 e confirmada pelo papa João XXII em 1319. Era uma ordem religiosa, com o papa como soberano, a despeito de a Coroa portuguesa exercer total controle sobre ela. Herdou os bens da Ordem dos Templários, e os recursos angariados eram utilizados nas viagens de descobrimento.

De acordo com Varela (2005, p. 73), o pressuposto das sesmarias no Brasil era o caráter público das terras, ou seja, "o fato dos territórios pertencerem de jure à Coroa, sob a jurisdição espiritual da Ordem de Cristo”. Para essa autora, a sesmaria na sociedade portuguesa era apenas uma das formas dominiais, mas, no Brasil, passou a ser regra geral. De fato, a doação das sesmarias era a única maneira de ascender à terra no território da colônia.

O regime de sesmarias especificou a história da apropriação ${ }^{2}$ da terra no país. Na maioria dos países colonizadores, a individualização da propriedade ocorreu em decorrência da ruptura com os deveres e obrigações do camponês para com o senhor feudal. No Brasil, entretanto, resultou da ruptura com a propriedade pública, representada pelo instituto da sesmaria.

Além disso, o não cumprimento das exigências de exploração da sesmaria implicava sua reversão, e é essa possibilidade de retomada da terra pelo proprietário/Coroa que, segundo Varela (2005), define as características da propriedade fundiária no início da colonização brasileira.

Conforme esclarece Paes (2018, p. 42), nesse período, e até meados do século XIX:

A posse - e não a titulação individualizada da propriedade - era o
centro dessas relações. A principal forma de reconhecimento de
uma relação jurídica legítima entre uma pessoa e uma coisa era feita
por meio da identificação do uso efetivo dessa coisa, mais do que
por meio da existência de um título individual de concessão de pro-
priedade. [...] Em outras palavras, o ambiente jurídico brasileiro das

2. Para Varela (2005, p. 86) trata-se "de uma forma de apropriação, que aqui denominamos 'propriedade' não absoluta, condicionada por inúmeros deveres, e que se aproxima de uma concessão ou privilégio”. 
primeiras décadas do século XIX não era pautado pela centralidade da noção de propriedade individualizada e titulada, mas pela convicção de que direitos eram adquiridos na medida em que eram exercidos.

Marés (2003, p. 27) endossa que, no sistema sesmarial, o "direito à terra [...] estava condicionado ao seu uso; à sua transformação”. O autor complementa: “[...] o primeiro documento comprobatório de propriedade privada da terra no Brasil é o título de concessão de sesmaria” (MARÉS, 2003, p. 63). É nesse sentido que Wehling (apud VÍCOLA, 2009, p. 92) afirma que o regime de sesmarias, e, portanto, o conceito de propriedade associado ao seu uso, configura-se como "a chave do regime de propriedade no Brasil até o século XIX”.

As Ordenações definiam um limite no tamanho das sesmarias, vinculando a concessão a uma área que o destinatário fosse capaz de aproveitar, dentro do prazo definido pela lei. No entanto, a precariedade do sistema de produção do Brasil Colônia, voltado ao atendimento das necessidades de Portugal, ocasionou o aumento das concessões de sesmarias, e a relação obrigatória entre tamanho e utilização efetiva deixou de vigorar. Isso ocorreu porque a estrutura da produção agrícola brasileira naquele período estava centrada no cultivo de cana-de-açúcar e engenhos, que exigiam grandes extensões de terra, áreas maiores do que as previstas nas regras das sesmarias portuguesas.

Na tentativa de regulamentar a expansão da área das sesmarias, eram expedidas cartas régias, nas quais se delimitavam extensões máximas de área, exigências para comprovação de uso e outros detalhes das concessões. Com o passar do tempo, configurou-se um conjunto de leis de difícil compreensão, e, como consequência, na segunda metade do século XIX, a organização territorial do Brasil se caracterizava por um número elevado de sesmarias não regulamentadas ou abandonadas diante das dificuldades de manutenção. Tornou-se comum, então, a apropriação dessas terras por "posseiros”, e isso gerou um sistema sem regras de ocupação de terras, que ocorria de forma associada às cessões das sesmarias. Eram frequentes, pois, discussões judiciais sobre delimitações de propriedades, o que levou à gradativa redução das concessões, até que, em 1822, as sesmarias foram definitivamente extintas.

A extinção do instituto das sesmarias ocorreu no mesmo momento em que o comércio internacional pressionava pelo fim do tráfico negreiro. A proibição da importação de escravizados aconteceu na sequência e interferiu no sistema produtivo brasileiro, provocando o início da discussão sobre uma legislação capaz de regulamentar o acesso à terra aos trabalhadores que viriam a ser libertos. 
Esse foi o contexto em que se aprovou a Lei ${ }^{\circ} 601$, de 1850 (BRASIL, 1850), que definia as condições para apropriação da terra no Brasil.

Varela relata que a Lei de Terras finalizou um "longo capítulo da história territorial do Brasil", ao eliminar a posse como modo predominante de acesso à terra e ao romper, assim, o "princípio do cultivo, de tão longa história no direito”. Para a autora, assentavam-se, com isso, as bases para "uma nova conformação do modelo proprietário” no país (VARELA, 2005, p. 118).

\section{A plenitude do direito de propriedade}

De acordo com Varela (2005), a aprovação da Lei de Terras obedecia a dois aspectos: possibilitar a transição do trabalho escravizado para o trabalho livre, consequência da suspensão do tráfico negreiro, e, ao mesmo tempo, permitir ao Estado imperial o controle sobre as terras devolutas, que, desde a extinção das sesmarias, estavam se tornando patrimônio privado. De acordo com a Lei de Terras (BRASIL, 1850), terras devolutas eram aquelas "que não tinham uso público nacional, provincial ou municipal; não se achavam no domínio particular; não foram dadas por sesmarias ou que não se achavam ocupadas por posse”.

Para efetivar esse período de transição, a Lei de 1850 buscou legitimar as posses existentes, mantendo como critério o cultivo efetivo, conforme seu artigo $4^{\circ}$ :

Serão revalidadas as sesmarias, ou outras concessões do Governo Geral ou Provincial, que se acharem cultivadas, ou com princípios de cultura, e morada habitual do respectivo sesmeiro ou concessionário, ou de quem os represente, embora não tenha sido cumprida qualquer das outras condições, com que foram concedidas. (BRASIL, 1850)

Ao mesmo tempo, a lei proibia a posse de terras devolutas e instituiu a compra como única forma de acesso, como constava no seu artigo $1^{0}$ : "Ficam proibidas as acquisições de terras devolutas por outro título que não seja o de compra" (BRASIL, 1850).

Segundo Fonseca (2005), a nova lei tinha o propósito de acabar com as formas tradicionais de acesso à terra (sesmarias e possessão), regularizando posses existentes até aquele momento, desde que cumpridas condições específicas relacionadas ao uso, e, sobretudo, diferenciando claramente as propriedades particulares e o domínio público. Para o autor, "a partir de então, finalmente, seria possível ver emergir de modo claro a figura do proprietário, quer fosse o proprietário particular, quer fosse o proprietário Estado" (FONSECA, 2005, p. 110). 
A Lei de Terras, portanto, confere estatuto jurídico à propriedade individual no Brasil, instituindo o título para isso; o uso deixa de ser o fundamento da propriedade e passa a haver uma separação entre domínio público e privado. Ao formalizar o título de propriedade como documento básico para a certificação, a lei modificou o conceito de propriedade: a comprovação do uso como critério de propriedade foi substituída pela comprovação de titulação, conforme esclarece Paes (2018, p. 43):

No Brasil, a posse prevaleceu como categoria estruturante das relações entre pessoas e coisas ao longo de grande parte do século XIX, sendo possível identificar o princípio de um processo de predominância do título como modo principal de aquisição e prova de direitos sobre as coisas, aproximadamente, na década de 1870.

A terra, até então propriedade pública - da Coroa -, torna-se individualizada e comercializada de acordo com o poder econômico do interessado. A lei previa a possibilidade de regularização da posse, valendo-se de procedimentos que culminavam na diplomação de um título, simbolizando, conforme Bürger e Capelotti (2017, p. 29), "o trajeto da informalidade dos fatos (simples posse) ao reino da formalidade do direito, da propriedade”. Considerada como algo individual, a propriedade passa a necessitar de um título para ser comprovada.

A concepção da propriedade como direito individual e pleno foi defendida na Constituição de 1824 e, na sequência, pela Constituição Republicana de 1891. Em ambas, o conteúdo do artigo competente é praticamente o mesmo, explicitando-se então que, em caso de utilidade pública, deveria ser paga indenização ao proprietário.

A Constituição de 1891 faz referência ao direito de propriedade no capítulo Declaração de Direitos, artigo 72, parágrafo 17: “O direito de propriedade mantém-se em toda a sua plenitude, salva a desapropriação por necessidade, ou utilidade pública, mediante indemnização prévia” (BRASIL, 1891; grifos da autora).

A Constituição de 1824 (BRASIL, 1824) também definia, no inciso XVII do artigo 179, que deveria ser elaborado um Código Civil, o qual foi aprovado somente em 1916. E, segundo Assis (2008), embora tenha sido inovador ao abordar a relação jurídica do direito de propriedade, ele apenas ratificou os conceitos anteriores.

No artigo 524, o Código Civil de 1916 dispõe: “A lei assegura ao proprietário o direito de usar, gozar e dispor de seus bens, e de reavê-los do poder de quem quer que injustamente os possua”. E o artigo 527 o complementa, ao definir que "o domínio se presume exclusivo e ilimitado, até prova em contrário” (BRASIL, 1916).

Para Soares (2018), apesar de o Código de 1916 estabelecer algumas limitações à propriedade, ao considerar o direito de vizinhança, não levou em conta 
limitações que estivessem relacionadas a direitos coletivos, uma vez que manteve a concepção individualista de propriedade, até então predominante.

\section{Algumas mudanças: propriedade e o bem-estar social}

Foi somente na Constituição de 1934 (BRASIL, 1934) que as normas legislativas apontaram que o direito de propriedade não poderia ser exercido contra o interesse social ou coletivo.

Esse conceito foi reproduzido na Constituição de 1937 (BRASIL, 1937), outorgada no contexto da instauração do Estado Novo ou Era Vargas, regime instaurado no Brasil após o golpe de Estado de Getúlio Vargas, compreendido entre 1937 e 1946. No seu artigo 122, a lei reforça que o direito de propriedade não pode se contrapor ao interesse social e também institui a possibilidade de desapropriação, a ser regulamentada por leis complementares.

A deposição do presidente Getúlio Vargas, em 1945, deu início à redemocratização do país, culminando com a Constituição de 1946, em cujo artigo 141, parágrafo 16, se estabelece que "é garantido o direito de propriedade, salvo o caso de desapropriação por necessidade ou utilidade pública, ou por interesse social, mediante prévia e justa indenização em dinheiro” (BRASIL, 1946).

Apesar da individualização da propriedade que esse parágrafo explicita, o artigo 147 da Constituição de 1946 vincula o conceito de propriedade ao bem-estar social: "O uso da propriedade será condicionado ao bem-estar social. A lei poderá, com observância do disposto no art. 141, § 16, promover a justa distribuição da propriedade, com igual oportunidade para todos” (BRASIL, 1946; grifo da autora).

Foi na Constituição de 1967 que apareceu pela primeira vez o termo "função social da propriedade”, como princípio da ordem econômica e social. Entretanto, a vinculação entre propriedade urbana e função social foi consolidada somente no texto da Constituição Federal (BRASIL, 1988), discutido na sequência.

\subsection{A função social da propriedade como princípio legítimo para definição} do uso do solo urbano

Para Silva (2010), a inserção do princípio da função social, contido no artigo 182 da Constituição Federal de 1988, modificou a natureza do direito de propriedade, que não pode mais ser visto como um direito individual. O autor destaca:

A função social manifesta-se na própria configuração estrutural do direito de propriedade, pondo-se concretamente como elemento qualificante na predeterminação dos modos de aquisição, gozo e utilização dos bens. [...] A inserção do princípio da função social, sem impedir a existência da instituição, modifica sua natureza. (SILVA, 2010, p. 72) 
Portanto, o conceito de propriedade vinculado à função social que esta desempenha determina que, além de direitos sobre a terra, estão vinculados deveres ao título de propriedade no tocante ao atendimento de interesses coletivos.

No mesmo sentido, Comparato (1986) afirma que o adjetivo "social", associado à palavra "função", indica que a carta constitucional vinculou a propriedade ao interesse coletivo. Nas palavras do autor, "essa função social da propriedade corresponde a um poder-dever do proprietário, sancionável pela ordem jurídica” (COMPARATO, 1986, p. 76).

Grau (1983, p. 65) confirma essa posição, ao afirmar que "não pode a propriedade ser usada de modo contrário à utilidade social, preservando-se o direito do proprietário somente enquanto o seu uso contrário ao interesse social não ocorrer”. Para Cardoso (2008, p. 103), a função social pode ser situada, em conformidade com a Constituição Federal de 1988, como "elemento intrínseco à propriedade”.

Elaborado na sequência da Constituição de 1988, o Código Civil, aprovado em 2002 (BRASIL, 2002) e vigente até hoje, explicita no seu artigo 1.225 o conceito de direito de propriedade como um direito real, o que significa considerá-lo tendo em vista as relações jurídicas do homem com os objetos que possui, contrapondo-se, portanto, ao direito pessoal, que trata das relações entre sujeitos.

Ao associar o direito de propriedade ao cumprimento de finalidades econômicas e sociais (artigo 1.228) e definir como ato ilícito o não cumprimento dessa finalidade (artigo 187), o Código Civil defende o interesse público, ficando subjugados a este os interesses individuais. A Constituição de 1988 e o Código Civil de 2002, portanto, estabeleceram limites e critérios para os direitos sobre a propriedade cuja observância é condição para a garantia da manutenção da propriedade.

O Código Civil determina, na opinião de Cardoso (2008), que a propriedade deve ser realizada sob o ponto de vista da função social do bem. Dessa maneira, pode-se inferir com relação à terra urbana que o poder de escolha do proprietário quanto ao uso a ser dado ao solo seria limitado pela necessidade de atender aos interesses sociais. $\mathrm{O}$ atendimento a esses interesses também incidiria sobre a fruição, ou seja, "na produção e destinação dos frutos oriundos da utilização dada ao imóvel pelo seu titular" (CARDOSO, 2008, p.109). O mesmo acontece com a disposição, uma vez que a legislação urbanística institui dimensões mínimas e parâmetros de ocupação para os imóveis urbanos. Dessa forma, para a autora, o ordenamento jurídico passou a restringir o caráter totalitário e individualista da propriedade urbana.

Os artigos 182 e 183 da Constituição Federal de 1988, que conformam o Capítulo II, da Política Urbana, foram regulamentados pela Lei federal $n^{\circ}$ 10.257/01, denominada Estatuto da Cidade. No parágrafo único do seu artigo $1^{\circ}$, lê-se: 
Para todos os efeitos, esta Lei, denominada Estatuto da Cidade, estabelece normas de ordem pública e interesse social que regulam o uso da propriedade urbana em prol do bem coletivo, da segurança e do bem-estar dos cidadãos, bem como do equilíbrio ambiental. (BRASIL, 2001)

Rabello (2016) afirma ser o Estatuto da Cidade a mais importante lei sobre direito urbanístico no país, em razão de materializar os princípios e as diretrizes nacionais da política urbana estabelecidos pela Constituição de 1988. Esclarece a autora que as normas que regulam o direito de propriedade, até o advento do Estatuto da Cidade, eram regulamentadas pelo Código Civil e "desprezava-se, por conseguinte, o efeito das normas urbanísticas municipais na modulação do conteúdo do direito de propriedade imobiliária urbana, especialmente quanto ao uso dessa propriedade" (RABELLO, 2016, p. 485).

A Constituição Federal de 1988 e o Estatuto modificam, portanto, a escala a ser considerada para o cumprimento do princípio da função social da cidade. Deixa-se de pensar essa função lote a lote, visto que "a unidade de regulação é a cidade como um todo" (RABELLO, 2001, p. 487). Segundo a autora, a legislação evoluiu na compreensão de que a regulação urbanística vai além da simples limitação administrativa do uso da propriedade. Ou seja, as leis urbanísticas não instituem limitações ao direito de propriedade; em vez disso, regulam o uso da cidade para que se faça cumprir a função social da propriedade.

\section{Direito de propriedade no Brasil: uma espiral do tempo}

Tomando como referência Paes (2018, p. 42), para quem "propriedade, posse e título são institutos jurídicos em constante transformação”, o quadro a seguir apresenta uma síntese cronológica da conformação do conceito de propriedade no Brasil, com o propósito de demonstrar que esse conceito não é imutável, que ele acompanha a dinâmica da sociedade.

Conforme discutido ao longo do texto, até o início do século XIX, o uso era o definidor da propriedade e do direito sobre ela. Esse conceito vai se modificando e a Lei de 1850 confirma o predomínio da compra para o acesso à terra. A partir de então, mantém-se o conceito da propriedade, e seus direitos, como algo passível de ser adquirido pela compra, desaparecendo o uso como fundamento. Do século XX até a atualidade, uma vertente importante das discussões sobre direito de propriedade enfatiza sua função social, numa tentativa de incorporá-lo à realidade urbana predominante no Brasil, onde convivem terras vazias e um crescente contingente populacional sem local para moradia. 
A linha do tempo apresentada a seguir reitera a ideia de Rabello (2016, p. 483), que discute a mutabilidade do conceito de direito de propriedade:

É isto que está acontecendo com o chamado direito de propriedade imobiliária urbana: uma adaptação à nova realidade onde ele se insere: na cidade. A interpretação tradicional do significado de seu conteúdo, que foi plausível para as cidades que tivemos até meados do século XX, já não mais se ajusta ao fenômeno e à sociedade urbana do século XXI. Só a evolução conceitual, por uma reinterpretação conceitual, o salvará; é o que está acontecendo no Brasil, e em outras partes do mundo.

\begin{tabular}{|c|c|c|c|c|c|}
\hline \multicolumn{2}{|c|}{ Período } & Normas & Conteúdo & Situação da terra & Comprovação \\
\hline \multicolumn{2}{|c|}{$\begin{array}{c}\text { Séc. XVI a séc. } \\
\text { XVIII }\end{array}$} & $\begin{array}{l}\text { Ordenações } \\
\text { Filipinas }\end{array}$ & $\begin{array}{c}\text { Sesmarias como forma de } \\
\text { acesso à terra }\end{array}$ & Coroa & \multirow{4}{*}{ uso/posse } \\
\hline \multirow{6}{*}{ Séc. XIX } & \multirow{2}{*}{1822} & $\begin{array}{l}\text { Resoluções } \\
\text { imperiais }\end{array}$ & Extinção das sesmarias & \multirow{3}{*}{ Império } & \\
\hline & & Cartas régias & \multirow{2}{*}{$\begin{array}{c}\text { Delimitação das antigas } \\
\text { sesmarias }\end{array}$} & & \\
\hline & 1824 & $\begin{array}{l}\text { Constituição do } \\
\text { Império }\end{array}$ & & & \\
\hline & \multirow[t]{2}{*}{1850} & \multirow[t]{2}{*}{ Lei de Terras } & $\begin{array}{l}\text { Legitimação das posses } \\
\text { existentes, mantendo como } \\
\text { critério o cultivo efetivo }\end{array}$ & \multirow{2}{*}{$\begin{array}{l}\text { Terras imperiais, } \\
\text { colocadas à venda }\end{array}$} & \multirow{11}{*}{$\begin{array}{l}\text { Título } \\
\text { propriedade }\end{array}$} \\
\hline & & & $\begin{array}{c}\text { Compra como forma de } \\
\text { acesso à terra }\end{array}$ & & \\
\hline & 1891 & $\begin{array}{l}\text { Constituição da } \\
\text { República }\end{array}$ & Propriedade plena & \multirow{9}{*}{ Privada } & \\
\hline \multirow{7}{*}{ Séc. XX } & 1916 & Código Civil & $\begin{array}{l}\text { Propriedade, com res-peito ao } \\
\text { direito de vizinhança }\end{array}$ & & \\
\hline & 1934 & Constituição & $\begin{array}{l}\text { Inserção do interesse coletivo } \\
\text { como limite à propriedade }\end{array}$ & & \\
\hline & 1937 & $\begin{array}{l}\text { Constituição do } \\
\text { Estado Novo }\end{array}$ & $\begin{array}{c}\text { Possibilidade de desapropriação } \\
\text { para fins de utilidade pública }\end{array}$ & & \\
\hline & \multirow{2}{*}{1946} & Constituição & \multirow{2}{*}{$\begin{array}{l}\text { Bem-estar social como limite } \\
\text { à propriedade }\end{array}$} & & \\
\hline & & pós-Estado Novo & & & \\
\hline & 1967 & $\begin{array}{l}\text { Constituição do } \\
\text { período militar }\end{array}$ & Função social da propriedade & & \\
\hline & 1988 & $\begin{array}{l}\text { Constituição } \\
\text { Cidadã }\end{array}$ & Propriedade como função social & & \\
\hline Séc. XXI & 2001 & $\begin{array}{l}\text { Estatuto da } \\
\text { Cidade }\end{array}$ & Operacionaliza a função social & & \\
\hline
\end{tabular}

Quadro 1. Trajetória da conformação do conteúdo da propriedade fundiária no Brasil Fonte: Elaborado pela autora, 2020. 
Ou seja, o conceito de direito de propriedade é continuamente (re)construído. Isso significa, conforme Coutinho, Prol e Miola (2018), que compreender as transformações ocorridas no conceito de propriedade é uma maneira de compreender a sociedade que o define.

\section{A propriedade e o comum: conceitos em transformação}

A exposição da trajetória do conceito de direito de propriedade no Brasil confirma a afirmação inicial de Rodota (1990), de que "de tempos em tempos há um renascimento da questão proprietária”. Na verdade, é possível complementá-la, com a noção de que a questão proprietária está sempre presente e de que sua relevância é ainda maior na contemporaneidade, quando a propriedade assume papel fundamental na estruturação das cidades.

Entretanto, esclarece Canestraro (2005, p. 17),

[...] a propriedade da terra não é apenas entre um indivíduo (o proprietário) e uma coisa (a terra), mas é uma relação social, entre sujeitos [...]. Longe de ser uma entidade estática, sua definição é fruto de um processo histórico que vai sendo definido de acordo com os conflitos pela apropriação e ocupação do solo. (tradução da autora)

E é justamente pelo fato de ser uma relação social que a propriedade se transforma no tempo, conforme Quadro 1. Azuela (1989), por sua vez, afirma que o caráter de relação social da propriedade tem estreito vínculo com a situação predominante em quase todas as cidades brasileiras: o crescimento das ocupações à margem da legalidade instituída. Isso porque o direito de propriedade vigente, individualista, se baseia no fato de que alguns (os proprietários) têm a capacidade de excluir outros (não proprietários) do uso, gozo e disposição de alguma coisa - nesse caso, a terra urbana.

Nesse contexto, a ocupação das periferias das cidades brasileiras poderia ser analisada segundo o processo por meio do qual se constituem e se transformam as relações de propriedade. Para Azuela (1989), considerar os assentamentos urbanos como irregulares ou ilegais significa ignorar as relações de propriedade neles existentes. Na verdade, o tipo de relação de propriedade aí predominante não se encaixa no conceito de propriedade constante nos textos jurídicos no Brasil. Porém, há uma relação de propriedade. As famílias constroem suas casas sobre um terreno e, inclusive, comercializam essas moradias. Usando as palavras de Canestraro (2005, p. 16), a relação de propriedade aí encontrada é "resultado de um processo histórico que se define em função dos conflitos pela apropriação e ocupação do solo" (tradução da autora). 
Fernandes e Alfonsin (2016) reiteram essa posição, ao afirmar que, na maioria das cidades do Brasil, grande parcela da população resolve o problema de moradia fazendo uso de processos que, de alguma maneira, desobedecem ao conceito normativo em vigor sobre propriedade. Para esses autores, a "ilegalidade" urbana deixou de ser exceção para se tornar a regra, estruturando o processo de produção da cidade. Em decorrência, gera-se um questionamento sobre a natureza da ordem jurídica vigente, que enfatiza a visão individual do direito de propriedade e define o que é legal e o que não é.

Vale, então, trazer para esta discussão a posição de Azuela (1989), para quem o Direito, por si, não é mais do que um tipo de discurso, que só ganha sentido e consistência se efetivado na prática social. Entretanto, o autor ressalta que:

Isso não significa dizer que as normas criam relações sociais, mas sim que elas lhes dão uma condição particular que qualquer um pode reconhecer quando distingue, em linguagem comum, entre uma situação de "fato" e uma "oficial". A lei fornece aos atores um repertório que lhes permite conferir um significado compartilhado às relações das quais participam, incluindo, é claro, as relações de propriedade. (AZUELA, 1989, p. 24; tradução da autora)

Em face desses pressupostos, e para refletir sobre as possibilidades de continuidade da linha do tempo do conceito de propriedade, a discussão posta por Dardot e Laval (2017, p. 199) é fundamental. Os autores indicam uma transformação, já em processo, das relações sociais que caracterizam o direito de propriedade. Para explicar essa transformação, utilizam o conceito de "comum”, traduzido como "designação de um regime de práticas, lutas, instituições e pesquisas que abrem as portas para um futuro não capitalista“ (DARDOT; LAVAL, 2017, p. 18). Eles afirmam que, no século XXI, "o princípio político do comum emerge das lutas democráticas e dos movimentos sociais. Inaugura-se com ele um novo tempo e emancipação. Está se formando um novo discurso teórico que, ligado aos movimentos altermundistas, bebe de fontes teóricas múltiplas” (DARDOT; LAVAL, 2017, p. 59).

Para discutir a relação do comum com a propriedade privada, Dardot e Laval discorrem sobre as possibilidades do surgimento de um novo Direito, que represente os conflitos sociais e que fortaleça o comum como um princípio político. Com vistas a contribuir para o avanço desse princípio, os autores apresentam proposições que se relacionam com a discussão conduzida neste trabalho:

3. Segundo Dardot e Laval (2017, p. 18): "Michael Hardt e Antonio Negri produziram a primeira teoria do comum, cujo mérito histórico foi o de levar a reflexão do plano das experiências concretas dos commons (no plural) para uma concepção mais abstrata e politicamente mais ambiciosa do comum (no singular)”. 
i) fazer do comum o princípio de transformação do social; ii) contrapor um novo direito de uso ao direito de propriedade; iii) mundializar o comum.

O segundo item, utilizando o embasamento fornecido pelos autores referidos, nos leva a discutir a sequência da linha do tempo de propriedade. Dardot e Laval (2017) recuperam um dos aspectos apontados no início deste texto: o fato de o direito de propriedade no Brasil ter nascido em decorrência do direito de uso. Nas antigas sesmarias, para ser considerado dono de uma terra, era preciso demonstrar o uso que se destinava a ela. Dardot e Laval (2017, p. 429) não propõem, no entanto, um retorno a antigos conceitos de propriedade. Muito pelo contrário, o foco da discussão seria a superação destes para, então, "criar novos direitos de uso que, pelo reconhecimento de uma norma social de inapropriabilidade, imponham limites à propriedade privada e, nesse sentido, façam-na recuar”.

A legitimação desses “novos direitos de uso" seria feita por meio de uma prática coletiva. E os autores complementam: “[...] embora seja verdadeiro que não se decreta um costume, é possível decidir a instituição de regras capazes de se tornarem costumes pela força da prática” (DARDOT; LAVAL, 2017, p. 430). Ou seja, trata-se de produzir regras de Direito (e aqui se inclui o direito de propriedade) mediante uma prática coletiva que se torne costume no longo prazo e, então, um comum.

Retomando a questão das cidades brasileiras, pode-se afirmar que é possível vislumbrar uma sequência para a linha do tempo da propriedade no urbano, com o surgimento de meios que facilitem a instituição de regras que se tornem costumes. Dardot e Laval denominam esse processo "práxis instituinte":

[...] a possibilidade de uma maneira de usar a cidade que não seria 'nem o reconhecimento retroativo do que já existe', nem uma 'criação a partir do nada', mas traz o novo à existência a partir das condições existentes e mediante transformação destas [...]. Para ter alguma chance de vir à luz, o direito do comum deve provir dessa práxis, e não contar apenas com a difusão espontânea dos usos. (DARDOT; LAVAL, 2017, p. 244)

A posição de Dardot e Laval coincide com a de Azuela (1989, p. 229), quando afirma que a "norma, uma vez produzida por uma prática [...] isto é, uma vez em vigor, é uma referência para práticas futuras e, em condições normais, é uma condicionante real dessas práticas” (tradução da autora).

Quais poderiam ser, então, as regras para um "novo direito de propriedade" que permitiriam a prática instituinte? Essa é a discussão proposta por este texto, ao recuperar a trajetória do direito de propriedade. Pois é justamente pelo fato de essa trajetória ser contínua, mas não necessariamente linear, que se pode afirmar 
que, ainda, não existem respostas à pergunta apresentada. Trata-se, com efeito, de uma agenda de pesquisa em construção.

Contudo, apesar desse contexto de incertezas conceituais, este estudo aponta alguns caminhos que, necessariamente, passam por novas regras de construção da cidade capazes de incorporar a questão do uso como condição para a (re)definição do direito de propriedade - ou, seguindo Dardot e Laval (2017, p. 429), novas regras que reconheçam relações sociais de propriedade que, incorporando o conceito de comum, "imponham limites à propriedade privada e, nesse sentido, façam-na recuar".

Outra pergunta se impõe: quais seriam as regras capazes de impor limites à propriedade privada? A resposta, trazida pela trajetória apresentada, permite identificar que o conceito de propriedade é regido por estatutos jurídicos que definem a relação entre pessoas e coisas, de acordo com a realidade social de cada período histórico.

$\mathrm{Na}$ atualidade, em que predomina a realidade urbana, está se tratando, portanto, do conjunto de regras que normatizam a vida na cidade. Essas mesmas regras, no passado, estavam inseridas nas Ordenações Filipinas e, no presente, se expressam na legislação municipal de controle do uso do solo urbano. Nesse sentido, afirma Rabello (2016, p. 488):

Ordenar o território é regular o uso deste objeto público - o território. Mas é nele, no território, onde também se materializa, neste mesmo espaço, o direito privado de propriedade imobiliária. Território, objeto público, e lote urbano, objeto da propriedade privada, acontecem no mesmo espaço, sobre o mesmo solo, e a existência de um não elimina a existência do outro [...]. Por conseguinte, cada lote irá acomodar seus usos privados aos interesses públicos explicitados na regulação territorial, cujo objetivo constitucional inafastável é alcançar e prover seus habitantes de qualidade de vida e de acesso às funções sociais da cidade.

A regulação territorial do uso do solo, portanto, traduz, no cotidiano urbano, o conceito de direito de propriedade, que é dinâmico e acompanha as transformações sociais.

Pode-se concluir, então, que as regras a que se referem Dardot e Laval, capazes de impor limites à propriedade privada, são urbanísticas e deverão traduzir práticas cotidianas de apropriação do solo. Na cidade brasileira contemporânea, tais práticas correspondem ao uso do solo para suprir a necessidade de moradia, ao uso do solo urbano como condição de sobrevivência.

Nesse sentido, o conceito de direito de propriedade e as normas urbanísticas exigem uma concepção articulada, que considere tanto os interesses privados 
como a identificação de necessidades coletivas. Isso significa que a continuidade da trajetória do conceito de propriedade indicaria a possibilidade de um conceito em função do uso e do reconhecimento dessas demandas cotidianas. Mas, para seguir na discussão sobre o que viria na continuidade da linha do tempo, impõe-se a discussão sobre o futuro da sociedade contemporânea. Para isso, Piketty (2019, s.p.) dá uma contribuição importante: sempre existem vários caminhos possíveis de organizar uma sociedade e as relações de poder e de propriedade dentro dela. Em particular, existem muitas maneiras de organizar as relações de propriedade no século XXI, e algumas podem constituir um salto muito mais real do capitalismo do que o caminho que consiste em prometer sua destruição sem se preocupar com o que se seguirá.

Para esse autor, as escolhas entre os caminhos possíveis (por exemplo, quanto ao conceito de direito de propriedade) dependem do que cada sociedade entende e aceita como justiça e também das relações de força entre os grupos sociais. Segundo Piketty (2019, s.p.), essas relações de força são, acima de tudo, intelectuais e ideológicas: "Em outras palavras, ideias e ideologias contam na história. Elas permitem permanentemente imaginar e estruturar novos mundos e sociedades diferentes. Múltiplas trajetórias são sempre possíveis”.

Com isso, o final deste trabalho aponta a possibilidade de sermos otimistas diante da cidade contemporânea, mediante a construção de uma utopia urbana positiva. Porque, de fato, "nenhum futuro pode ser visto com otimismo se não inserirmos nessa visão uma dose de utopia. Não a utopia como sonho irrealizável, mas como um projeto de ações, capaz de materializar esse sonho" (PEREIRA, 2002, p. 3). Huyssen (2001, p. 247, 256) complementa essa afirmação:

[...] o pensamento utópico sempre sobreviveu a enterros prematuros e, em determinadas épocas até protagonizou ressurreições bastante espetaculares a partir dos não lugares dos mapas da vida social e cultural [...]. O postulado atual de que a utopia acabou não é mais plausível hoje [...] e cairá no esquecimento assim que ressurgir a próxima sensibilidade utópica. (tradução da autora).

Toda utopia apresenta dois polos: de um lado, faz uma crítica da situação existente; de outro, propõe como as coisas deveriam ser. Teria sentido, então, pensar que a linha do tempo da propriedade poderia ter continuidade mediante a construção de uma utopia: o comum, defendido por Dardot e Laval (2017) - o qual poderia constituir-se como uma (e próxima) "sensibilidade utópica".

Não seria, porém, uma propriedade comum, mas, conforme os referidos autores, a redefinição do direito de uso: 
[...] mesmo que haja um direito de uso previamente reconhecido, seu exercício só poderá ser precário enquanto os direitos de uso e os direitos de decisão das regras desse uso estiverem artificialmente dissociados: o direito de uso não tem nenhuma efetividade se estiver desvinculado do direito de coproduzir as regras do uso comum. (DARDOT; LAVAL, 2017, p. 504)

A trajetória do conceito de propriedade (e utopia a ser socialmente construída) avançaria, desse modo, para o direito de construir em comum o uso da terra: “O uso instituinte dos comuns não é um direito de propriedade: ele é a negação em ato do direito de propriedade em todas as suas formas, porque é a única forma de lidar com o inapropriável” (DARDOT; LAVAL, 2017, p. 509).

Com esses pressupostos, seria possível reorganizar os dados do Quadro 1, relativo à trajetória do conceito de direito de propriedade, transformando-os na Figura 1, que aponta para um futuro por vir.

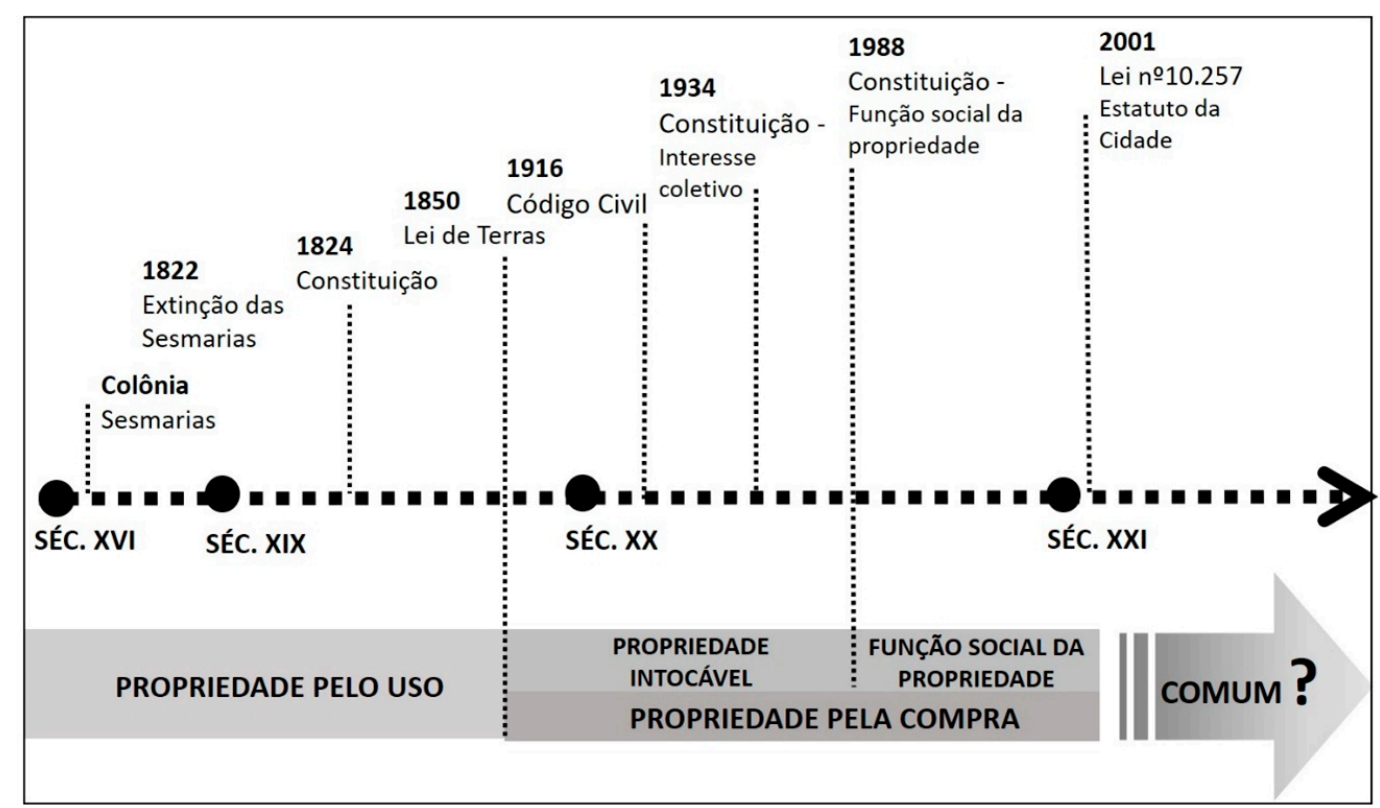

Figura 1. Síntese da linha do tempo da propriedade no Brasil Fonte: Elaborado pela autora, 2020.

Nesse contexto, pensar o urbano contemporâneo exigiria repensar os processos de construção da cidade por meio da aplicação de regras que facilitem a práxis instituinte do comum e a recuperação do uso como critério fundamental, segundo a "codeterminação dos fins desse uso por aqueles que efetivamente ocupam a terra urbana” (DARDOT; LAVAL, 2017, p. 507). Esse seria, portanto, o desafio apresentado por este texto. 


\section{Considerações finais: Propriedade urbana - uma trajetória em aberto}

A trajetória do conceito de propriedade que este texto apresenta partiu do pressuposto da existência de um corpo jurídico que expressa as regras da sociedade que o define. Como afirma Rabello (2001, p. 111): "Se a construção do sistema jurídico do urbanismo deve garantir, por um lado, a segurança das relações jurídicas, por outro deve procurar atender, pela adequação da norma, às múltiplas situações fáticas mutáveis, que se apresentam na vida urbana”.

A situação fática a que se refere a autora é a realidade urbana predominante na maioria das grandes cidades do Brasil: ocupação da terra sem um título de propriedade juridicamente válido, mas validado pelo uso.

Este texto é finalizado, então, com a formulação de um convite: a formatação de uma agenda de pesquisa que considere a (re)construção de normas de uso e ocupação do solo urbano que permitam a práxis instituinte; de normas que tenham o uso como condição para o direito de propriedade, ou, de acordo com o discutido aqui, que reconheçam como legítimas as relações de propriedade habilitadas a incorporar o conceito de comum.

É uma citação de Chauí (2000, p. 466) que fundamenta esse convite: “O possível não é o provável. Este é o previsível, isto é, algo que podemos calcular e antever, porque é uma probabilidade contida nos fatos e nos dados que analisamos. $\mathrm{O}$ possível, porém, é aquilo criado pela nossa própria ação. É o que vem à existência graças ao nosso agir”.

Por fim, é preciso destacar que este trabalho não abarcou todos os problemas e questões existentes no que diz respeito à discussão sobre as relações de propriedade. Apenas foram reconhecidos os momentos-chave e os aspectos essenciais do processo de conformação da propriedade como um direito, para que, com base nisso, seja possível identificar novos direcionamentos para a trajetória desse conceito.

\section{Referências}

ALMEIDA, C. M. Ordenações Filipinas. Lisboa: Fundação Calouste Gulbenkian, 1985.

ASSIS, L. G. B. A evolução do direito de propriedade ao longo dos textos constitucionais. Revista da Faculdade de Direito da Universidade de São Paulo, v. 103, p. 781-791 jan.-dez. 2008.

AZUELA, A. La ciudad, la propiedad privada y el derecho. Mexico, DF: El Colegio de Mexico, 1989.

BRASIL. Presidência da República. Casa Civil. Subchefia para Assuntos Jurídicos. Constituição Política do Império do Brasil. Manda observar a Constituição Politica do Imperio, offerecida e jurada por Sua Magestade o Imperador. Coleção de Leis do Império do Brasil, 1824. Disponível em: http://www.planalto.gov.br/ccivil_03/constituicao/constituicao24. htm. Acesso em: jan. 2019. 
BRASIL. Presidência da República. Casa Civil. Subchefia para Assuntos Jurídicos. Lei no 601, de 18 de setembro de 1850. Dispõe sobre as terras devolutas do Império. CLBR de 1850. Disponível em: http://www.planalto.gov.br/ccivil_03/leis/lo601-1850.htm. Acesso em 23 jan. 2019.

Presidência da República. Casa Civil. Subchefia para Assuntos Jurídicos. Constituição da República dos Estados Unidos do Brasil. 1891. Diário Oficial da União, 24 fev. 1891. Disponível em: http://www.planalto.gov.br/ccivil_03/Constituicao/Constituica091.htm. Acesso em: jan. 2019.

Presidência da República. Casa Civil. Subchefia para Assuntos Jurídicos. Lei ${ }^{\circ}$ 3.071, de $1^{\circ}$ de janeiro de 1916. Código Civil Nacional. Diário Oficial da União, 5 jan. 1916. Disponível em: http://www.planalto.gov.br/ccivil_03/leis/L3071.htm. Acesso em: jan. 2019.

Presidência da República. Casa Civil. Subchefia para Assuntos Jurídicos. Constituição da República dos Estados Unidos do Brasil. 1934. Diário Oficial da União, 16 jul. 1934. Disponível em: http://www.planalto.gov.br/ccivil_03/constituicao/constituica034.htm. Acesso em: nov. 2018.

Presidência da República. Casa Civil. Subchefia para Assuntos Jurídicos. Constituição da República dos Estados Unidos do Brasil. 1937. Diário Oficial da União, 10 nov. 1937. Disponível em: http://www.planalto.gov.br/ccivil_03/Constituicao/Constituica037.htm. Acesso em: jan. 2019.

Presidência da República. Casa Civil. Subchefia para Assuntos Jurídicos. Constituição da República dos Estados Unidos do Brasil. 1946. Diário Oficial da União, 19 set. 1946. Disponível em: http://www.planalto.gov.br/ccivil_03/constituicao/constituica046.htm. Acesso em: dez. 2018.

Presidência da República. Casa Civil. Subchefia para Assuntos Jurídicos. Constituição da República Federativa do Brasil. 1988. Disponível em: http://www.planalto.gov.br/ccivil_03/constituicao/constituicao.htm. Acesso em: jan. 2019.

Presidência da República. Casa Civil. Subchefia para Assuntos Jurídicos. Lei $n^{\circ}$ 10.257/2001 - Estatuto da Cidade. Regulamenta os arts. 182 e 183 da Constituição Federal, estabelece diretrizes gerais da política urbana e dá outras providências. Diário Oficial da União, Brasília, DF, 11 jul. 2001. Disponível em: http://www.planalto.gov.br/ ccivil_03/leis/leis_2001/110257.htm. Acesso em: jan. 2019.

Presidência da República. Casa Civil. Subchefia para Assuntos Jurídicos. Código Civil Nacional. Lei $\mathrm{n}^{0}$ 10.406, de 10 de janeiro de 2002. Diário Oficial da União, Brasília, DF. 11 jan. 2002. Disponível em: http://www.planalto.gov.br/ccivil_03/leis/2002/110406. htm. Acesso em: jan. 2019.

BÜRGER, M. L. F; CAPELOTTI, J. P. O percurso da posse e da propriedade no Brasil: das sesmarias aos conceitos contemporâneos. In: ANIMA: Revista Eletrônica do Curso de Direito das Faculdades OPET, Curitiba, ano IX, n. 16, jan.-jun. 2017.

CANESTRARO, M. L. De “formas” y “normas” en la apropiación del espacio. Reflexiones para una sociología urbana crítica. IV JORNADAS DE SOCIOLOGÍA DE LA UNLP, 2005. La Plata, Argentina. Memoria Académica. La Plata: UNLP, 2005. Tema: Desigualdad social, movimientos sociales, política e instituciones. Disponível em: http://www.memoria. fahce.unlp.edu.ar/trab_eventos/ev.6593/ev.6593.pdf. Acesso em: 15 nov. 2018. 
CARDOSO, F. L. Propriedade urbana no ordenamento brasileiro. Revista de Direito Administrativo, Rio de Janeiro, v. 247, p. 98-125, jan. 2008. Disponível em: http://bibliotecadigital.fgv.br/ojs/index.php/rda/article/view/41549/40862. Acesso em: 11 mar. 2019.

CHAUÍ, M. Convite à Filosofia. São Paulo: Ática, 2000.

COMPARATO, F. K. Função social da propriedade dos bens de produção. Revista dos Tribunais, v. 25, n. 63, p. 71-79, jul.-set. 1986. Disponível em: https://edisciplinas.usp.br/pluginfile. php/1894637/mod_resource/content/o/05\%20COMPARATO.\%20Funcao\%2osocial\%20 da\%2opropriedade\%2odos\%2obens\%20de\%2oproducao.pdf. Acesso em: 8 out. 2020.

COSTALDELLO, A. C. As transformações do regime jurídico da propriedade privada: a influência no direito urbanístico. Revista da Faculdade de Direito da UFPR, Curitiba, dez. 2006. Disponível em: https://revistas.ufpr.br/direito/article/view/8754. Acesso em: 2 jan. 2019 .

COUTINHO, D.; PROL, F.; MIOLA, I. (org.). Propriedades em transformação: abordagens multidisciplinares sobre a propriedade no Brasil. São Paulo, Edgard Blücher, 2018.

DARDOT, P.; LAVAL, C. Comum: ensaio sobre a revolução no século XXI. São Paulo: Boitempo, 2017.

FERNANDES, E.; ALFONSIN, B. (org.). Apresentação. In: FERNANDES, E. et al. Construção do Direito Urbanístico na América Latina. Belo Horizonte: Gaia Cultural, 2016. [livro eletrônico].

FERRI, C. A. A função social da propriedade rural e seu alcance difuso e coletivo. 2014. Dissertação (Mestrado) - Programa de Pós-graduação em Direito, Faculdade de Direito da Universidade Metodista de Piracicaba, Piracicaba, 2014.

FONSECA, R. M. A Lei de Terras e o advento da propriedade moderna no Brasil. 2005. Disponível em: https://studylib.es/doc/5170914/a-lei-de-terras-e-o-advento-da-propriedade-moderna. Acesso em: 7 fev. 2019.

GRAU, E. R. Direito urbano: regiões metropolitanas, solo criado, zoneamento e controle ambiental. São Paulo: Ed. Revista dos Tribunais, 1983.

HUYSSEN, A. En busca del futuro perdido. Cultura y memoria en tiempos de globalización. Buenos Aires: Fondo de Cultura Económica de Argentina, 2001.

MARÉS, C. F. A função social da terra. Porto Alegre: Sergio Antonio Fabris. 2003.

NOZOE, N. Sesmarias e apossamento de terras no Brasil Colônia. Revista Economia, São Paulo, FEA-USP, set.-dez. 2006.

PAES, M. A. D. Das cadeias dominicais impossíveis: posse e título no Brasil Império. In: UNGARETTI, D. et al. (ed.). Propriedades em transformação: abordagens multidisciplinares sobre a propriedade no Brasil. São Paulo: Blucher, 2018. p. 41-58.

PEREIRA, G. Produção da cidade e degradação do ambiente: a realidade da urbanização desigual. 2002. Tese (Doutorado em Meio Ambiente e Desenvolvimento) - Universidade Federal do Paraná, Curitiba, 2002.

PIKETTY, T. Capital et idéologie. Extratos. Tradução: André Langer. Le Monde: Paris, 2019. 
RABELLO, S. Regulação do território e da propriedade imobiliária urbana: evolução conceitual no Direito Brasileiro. In: FERRARI, S.; MENDONÇA, J. V. (org.). Direito em público. Rio de Janeiro: Lumen Juris, 2016.

. O poder de polícia normativo, o direito urbanístico e as normas de planejamento urbano. 2001. Tese elaborada como requisito parcial para o concurso ao cargo de Professor Titular de Direito Administrativo da Faculdade de Direito da Universidade do Estado do Rio de Janeiro, Rio de Janeiro, 2001. Disponível em: http://www.soniarabello.com.br/ wp-content/uploads/2012/06/O-Poder-de-Pol\%C3\%ADcia-Normativo-o-Direito-Urban\%C3\%ADstico-e-as-normas-de-Planejamento-Urbano.pdf. Acesso em: mar. 2019.

SILVA, J. A. da. Direito urbanístico brasileiro. São Paulo: Malheiros, 2010.

SOARES, V. B. N. O direito de propriedade: caracterização na concepção de autores clássicos e contemporâneos e breves comentários acerca da função social. Disponível em: https:// www.diritto.it/o-direito-de-propriedade-caracterizacao-na-concepcao-de-autores-classicos-e-contemporaneos-e-breves-comentarios-acerca-da-funcao-social/. Acesso em: 15 nov. 2018

VARELA, L. B. Das sesmarias à propriedade moderna: um estudo de história do direito brasileiro. Rio de Janeiro: Renovar, 2005.

VÍCOLA, N. S. A propriedade imobiliária no Brasil: breve histórico. Revista Eletrônica FMU Direito, v. 23, n. 31, 2009. 


\section{Gislene Pereira}

Arquiteta e urbanista pela Universidade Federal do Paraná (UFPR). Mestre em Planejamento Urbano e Regional pelo Instituto de Pesquisa e Planejamento Urbano e Regional da Universidade Federal do Rio de Janeiro (IPPUR/UFRJ). Doutora em Desenvolvimento e Meio Ambiente pelo MADE/UFPR. Docente titular no curso de Arquitetura e Urbanismo e no Programa de Pós-graduação em Planejamento Urbano (PPU) da UFPR. Pesquisadora na temática do planejamento urbano, com ênfase em políticas e instrumentos para financiamento do desenvolvimento urbano.

Email: gislenepereira42@gmail.com

ORCID: 0000-0003-0426-8314

Submissão: 9 de junho de 2020.

Aprovação: 14 de dezembro de 2020.

Como citar: PEREIRA, G. Das ordenações ao ordenamento: a trajetória do direito de propriedade no Brasil. Revista brasileira de estudos urbanos e regionais. v. 23, E202105pt, 2021. DOI 10.22296/2317-1529.rbeur.202105pt

Artigo licenciado sob Licença Creative Commons CC BY 4.0.

https://creativecommons.org/licenses/by/4.o/deed.pt_BR 